\title{
Plexiform Fibrohistiocytic Tumor
}

National Cancer Institute

\section{Source}

National Cancer Institute. Plexiform Fibrohistiocytic Tumor. NCI Thesaurus. Code C6493.

An intermediate cutaneous fibrohistiocytic neoplasm that usually affects children and young adults. It is a multinodular, poorly circumscribed tumor characterized by the presence of multinucleated giant cells, mononuclear histiocyte-like cells, and spindle fibroblast-like cells arranged in a plexiform pattern. 